\title{
ASYMPTOTIC BEHAVIOR OF POSITIVE SOLUTIONS OF A LANCHESTER-TYPE MODEL
}

\author{
Tran Thi Huyen Trang AND HiRoyuki UsAmi
}

Abstract. An ordinary differential system, referred to as Lanchester-type model, is treated. We examine how asymptotic behavior of every solution of the system varies according to the initial data. We can show the existence of critical values for initial data.

Mathematics subject classification (2010): 34C11,35E10.

Keywords and phrases: Asymptotic behavior, positive solution, Lanchester-type model.

\section{REFERENCES}

[1] M. J. ARTElLi AND R. F. DeCKRo, Modeling the Lanchester laws with system dynamics, J. Defence Modeling and Simulation 5, 1 (2008), 1-20.

[2] P. S. CHEN AND P. CHU, Applying Lanchester's linear law to model the Ardennes campaign, Naval. Res. Logist. 48 (2001), 653-661.

[3] D. R. Howes AND R. M. ThRALL, A theory of ideal linear weights for heterogeneous combat forces, Naval Research Logistics Quartery 20 (1973), 645-659.

[4] G. IS AC AND A. GossELIN, A military application of viability: winning cones, differential inclusions, and Lanchester type models for combats, Pareto Optimality, Game Theory and Equilibria, 759-797, Springer Optim. Appl., 17, Springer, New York 2008.

[5] I. R. JoHNSON AND N. J. MACKAY, Lanchester models and the Battle of Britain, Naval Res. Logist. 58 (2011), 210-222.

[6] K. Y. LIN AND N. J. MACKAY, The optimal policy for the one-against-many heterogeneous Lanchester model, Oper. Res. Lett. 42 (2014), 473-477.

[7] F. W. LANCHESTER, Aircraft in Warfare: The Dawn of the Fourth Arm, 1916 (Reprinted by Forgotten Books, 2015).

[8] M. B. SchAFFER, Lanchester models of guerrilla engagements, Santa Monica, California: The RAND Corporation, RM-5053-ARPA, DTIC\#AD648863, 1967.

[9] J. G. TAYLOR, Battle-outcome prediction conditions for variable-coefficient Lanchester-type equations for area fire, J. Franklin Inst. 311 (1981), 151-170.

[10] J. G. TAYLOR, Battle-outcome prediction for an extended system of Lanchester-type differential equations, J. Math. Anal. Appl. 103 (1984), 371-379. 